\title{
LA SEGURIDAD SOCIAL EN LA AGENDA DEL NEOLIBERALISMO EN ARGENTINA (1978-1993): SUS PROPUESTAS DE REFORMA, RESISTENCIAS Y DEBATES
}

\section{SOCIAL SECURITY IN THE AGENDA OF NEOLIBERALISM IN ARGENTINA (1978 - 1993): ITS REFORM PROJECTS, OPPOSITIONS AND ARGUMENTS}

\author{
Nicolás Dvoskin \\ Centro de Estudios e Investigaciones Laborales - \\ Consejo Nacional de Investigaciones Científicas y \\ Técnicas (CEIL-CONICET), \\ Buenos Aires, Argentina
}

\section{RESUMEN}

Este trabajo pretende analizar una cara particular del arribo de las ideas neoliberales a Argentina y América Latina: las reformas y proyectos de reforma de la seguridad social, principalmente del sistema previsional, desde fines de los setenta hasta principios de los noventa. Nos referimos al período que va desde el de las primeras propuestas de reforma claramente neoliberal de los sistemas de pensiones entre 1978 y 1979 -en dictadura- hasta la concreción de ese sueño en 1993 -en democracia.

El objetivo es analizar los fundamentos teóricos expuestos en los debates, para así dar cuenta del arribo del neoliberalismo en su clave discursiva, es decir, de la legitimación de la discursividad neoliberal.

Palabras clave: neoliberalismo, seguridad social, sistemas de pensiones, discursos hegemónicos, Argentina.

\begin{abstract}
This paper aims to analyse a specific aspect of the arrival of neoliberal ideas in Argentina and Latin America: social security reforms and reform projects, especially in the field of old-age pension systems, from the late 1970s until the early 1990s. This period began with the first clearly neoliberal proposals to reform the pension system between 1978 and 1979 (in times of dictatorship) and continued until the fulfillment of this dream in 1993 (under a democratic government).

Our goal is to analyse the theoretical foundations put forward in the debates, so as to study the arrival of neoliberalism in discursive terms, in other words the legitimisation of neoliberal discourse.
\end{abstract}

Keywords: neoliberalism, social security, pension system, hegemonic discourses, Argentina. 


\section{Presentación}

El presente trabajo pretende analizar una faceta no muy difundida del arribo de las ideas neoliberales a América Latina ly a Argentina en particular): las reformas y proyectos de reforma de la seguridad social, principalmente del sistema previsional, desde fines de los setenta hasta principios de los noventa. Nos referimos al período que va desde el esbozo y puesta en debate de las primeras propuestas de reforma claramente neoliberal de los sistemas de pensiones entre 1978 y 1979 -en tiempos de dictadura militar- hasta la concreción de ese sueño en 1993 -en tiempos democráticos-. Por supuesto, la delimitación del período que se realiza aquí no pretende ser comprendida como un encuadramiento de los años neoliberales. Esta no surge de la historia del neoliberalismo a secas sino de la historia previsional, pero esta última permite, precisamente, contribuir a la propia periodización del neoliberalismo latinoamericano, en especial al pasaje del neoliberalismo autoritario al neoliberalismo democrático, de los setenta a los noventa.

En términos metodológicos, se trata de una propuesta historiográfica que tiene como principal objetivo analizar los fundamentos teóricos expuestos en los distintos debates, para así dar cuenta no sólo del arribo del neoliberalismo en su clave fáctica -la más usual en el campo de la historia económica: políticas implementadas y resultados obtenidos- sino principalmente de su clave discursiva. En este sentido, nos interesa analizar, ante todo, cómo se llevó a cabo el proceso de legitimación de la discursividad neoliberal, al punto de permitirse en tiempos democráticos una reforma que no pudo implementarse en tiempos dictatoriales. En este sentido, las fuentes son, principalmente, los textos de los documentos públicos de las propuestas, discursos, versiones taquigráficas de las discusiones legislativas (para tiempos democráticos, claro está) y distintas notas periodísticas de las jornadas de los debates. 
En cuanto a los episodios (debates) analizados incluimos a) los análisis de dos propuestas de creación de un sistema previsional de capitalización surgidas de organismos que funcionaban como satélites del Ministerio de Economía durante la dictadura, la Universidad CEMA y la Bolsa de Comercio de la Ciudad de Buenos Aires, entre 1978 y 1979 y sus resistencias tanto internas al régimen de facto como externas; b) los conflictos que despertó la decisión del Ministerio de Economía de eliminar las contribuciones patronales a la seguridad social en 1980; c) el intento de recuperación de una seguridad social inclusiva en un contexto de pobreza e informalidad laboral crecientes y cajas flacas hacia el retorno de la democracia en 1983 y d) las discusiones que llevaron, hacia 1993, a la sanción de la Ley 24.241, que crea el sistema previsional mixto, con opción entre capitalización y reparto.

En términos de organización del artículo, el acápite 2 plantea una breve síntesis de la historia de la seguridad social antes del neoliberalismo, el 3 se refiere al neoliberalismo en tiempos autoritarios (1978-1983), el 4 al neoliberalismo en tiempos democráticos (1983 - 1993) y el 5 a las conclusiones. En líneas generales, se pretenderá contribuir a la idea de que el arribo del neoliberalismo en Argentina no fue un episodio puntual, sino que le llevó casi dos décadas consagrar su programa desde el momento en el que un ministro de Economía perteneciente a la tecnocracia neoliberal asumió su cargo, en marzo de 1976, atravesando enfrentamientos corporativos, ideológicos $y$, sobre todo, dificultades para legitimarse socialmente. En este sentido, aquí pretendemos dar cuenta de la trayectoria de la consolidación del neoliberalismo como paradigma político y económico, pero sobre todo discursivo, en Argentina, utilizando el caso de la seguridad social como un ejemplo.

\section{El punto de partida: la seguridad social argentina antes del neOlibe- RALISMO}

Si bien, como afirmamos hace algunas líneas, no podemos hablar del arribo del neoliberalismo como un episodio puntual sino como un proceso, podemos sostener -compartiendo una tesis mayoritaria en la historiografía económica argentina'- que el primer gobierno cuyas políticas económicas pueden inscribirse teórica, ideológica y discursivamente en el campo del neoliberalismo es el que asume el poder a través de un golpe de Estado

1 Por ejemplo, en las periodizaciones de la historia económica argentina que proponen Mario Rapoport (2012) o Eduardo Basualdo (2006). 
perpetrado por las fuerzas armadas el 24 de marzo de 1976, cuyo ministro de Economía durante los primeros años será José Alfredo Martínez de $\mathrm{Hoz}$, un empresario ligado a las corporaciones terratenientes de la Pampa Húmeda, perteneciente a la alta oligarquía de Buenos Aires.

Hemos analizado en otros textos la historia de la seguridad social argentina antes de la dictadura ${ }^{2}$ y nos proponemos hacer aquí un breve resumen. En líneas generales, proponemos nominar al período que va desde el golpe de Estado que derroca a Perón en 1955 hasta el inicio de la dictadura de 1976 como el de los años "desarrollistas", entendiendo una definición amplia del término ${ }^{3}$. La principal característica de la seguridad social argentina era su heterogeneidad institucional. Los distintos subsistemas (jubilaciones, asignaciones familiares, cobertura médica) corrían por canales institucionales distintos, y otros no existían, como por ejemplo los seguros de desempleo. Más aun, al interior de cada subsistema coexistían múltiples criterios por sectores, más allá de que en los últimos años se habían llevado a cabo algunas políticas tendientes a unificar y homogeneizar los subsistemas. Una de las políticas de institucionalización consistió en la creación del Ministerio de Bienestar Social en 1966, durante el gobierno de facto de Juan Carlos Onganía. Esta nueva cartera unificaría un conjunto de institutos y direcciones encargadas tanto de lo que hoy llamamos seguridad social como de lo que entendemos por política social o política asistencial, y estaría dirigida por sectores vinculados al mundo católico, principalmente a sectores que promulgaban con las ideas de la doctrina social de la iglesia.

2 La historia de la seguridad social argentina hasta los años sesenta fue trabajada en Dvoskin (2015b). A su vez, el período que se abre desde principios de los setenta hasta el golpe de Estado, con particular énfasis en los gobiernos de Cámpora y Perón entre 1973 y 1974 fue trabajado en Dvoskin (2014a). Un recorrido de largo plazo pero ceñido a la historia de las ideas principales -y sobre todo los principales textos en los que se fundamentaron los sistemas y las propuestas- es el que hemos realizado en Dvoskin (2015a).

3 Usualmente el término "desarrollista" suele aplicarse al pensamiento de Arturo Frondizi o Rogelio Frigerio, o a las políticas económicas aplicadas por el primero, entre 1958 y 1962. Aquí proponemos una definición amplia, que abarque la totalidad del período, y que se base, ante todo, en la primacía del proyecto industrialista con énfasis en la sustitución de importaciones, el eje mercadointernista de la política económica, la convocatoria a inversiones extranjeras para incrementar la oferta de bienes y aumentar la productividad y la legitimación tanto de los derechos sociales -al trabajo, la educación, la salud, la vivienda- como de sus actores corporativos principales -sindicatos, cámaras empresariales, iglesia- en tanto interlocutores válidos. De estos elementos se deriva, claro está, la búsqueda de una convivencia pacífica entre capital trabajo. 
Para el caso de las jubilaciones, desde siempre el principal subsistema de la seguridad social -en términos de beneficiarios y de montos recaudados y gastados-, el origen fragmentario asociado a conquistas gremiales puntuales dio pie a una intervención armonizadora en 1944 con la creación del Instituto Nacional de Previsión Social para llegar a la estatización definitiva recién en 1969, durante el ya mencionado gobierno militar. Al mismo tiempo, esta misma reforma -plasmada en los decretos-ley 18.037 y 18.038- consagró al sistema de reparto como el mecanismo de asignación de haberes previsionales, en desmedro de la lógica de la capitalización en cajas sindicales con la que se había constituido el sistema, si bien desde hacía muchos años en la práctica funcionaba un sistema de reparto. De hecho, uno de los principales elementos que hacían que antes de 1969 la formal capitalización fuera sustituida por el efectivo reparto era el persistente déficit, que obligaba al Estado a intervenir. Desde mediados de los años cuarenta algunas cajas ya empiezan a mostrar déficits persistentes, en 1962 se verifica el primer déficit general de todo el sistema, y desde 1966 el mismo será permanentemente deficitario.

A partir de 1970, tras la caída de Onganía, la gestión de la seguridad social permanecerá a cargo del Ministerio de Bienestar Social, el cual seguirá estando conducido por sectores vinculados al mundo corporativo católico. Con cambios de nombres, la conducción del Ministerio mostrará una continuidad política que llegará, de hecho, hasta los años ochenta, atravesando democracias y dictaduras. Entre 1970 y 1972 -período que se da a conocer como la segunda fase de la Revolución Argentina- la figura central será Francisco Manrique, quien avanzará levemente con algunos atisbos de protección no contributiva, pero quien, por sobre todas las cosas, promoverá la difusión y mediatización de las actividades del Ministerio, por ejemplo en la organización del $V$ Congreso lberoamericano de Seguridad Social, llevado a cabo en Buenos Aires en 1972, el cual contó con la presencia-como invitado de honor- de Licinio De la Fuente, ministro de Trabajo de la España franquista y reconocido dirigente falangista.

El período que se abre con el retorno de la democracia a principios de 1973 mostrará una seguridad social en disputa entre las dos facciones que componen al gobierno peronista: aquella ligada al empresariado nacional y a ciertas facciones políticas de izquierda peronista, que estará a cargo del Ministerio de Economía -bajola gestión de José Ber Gelbard-y aquella ligada a los sindicatos tradicionales, a lo que se conoce como derecha peronista y a la derecha católica, la cual estará a cargo del Ministerio de Bienestar Social -bajo la gestión de José López Rega-. En un período de abierta conflictividad política-que se agudizará con la muerte de Perón en julio de 1974- la agenda de la seguridad social no estuvo ajena a estas disputas. Mientras el 
proyecto de Gelbard estaba orientado a incluir a lo social en la agenda de la planificación del desarrollo -lo que queda claro, sobre todo, en la redacción del Plan Trienal de Reconstrucción y Liberación Nacional 1974-1977, presentado en diciembre de 1973-, el programa de López Rega pensaba una seguridad social que permanezca atada a sus lazos corporativos sindicales, reconociendo, sin embargo, la necesidad de avanzar hacia protecciones no contributivas para ciertos sectores postergados. En lo que sí tendieron a coincidir los proyectos de ambos sectores fue en la necesidad de expandir la hasta el momento muy precaria cobertura de asignaciones familiares -no así de los seguros de desempleo, que siguieron sin existir-.

Quizás el período que va desde mediados de los sesenta hasta los albores del golpe militar permite dar cuenta de la caída en desgracia de las utopías del desarrollismo, aquellas que, con un optimismo pocas veces visto, entendían que la llegada de inversiones extranjeras y el aumento de la productividad traerían como resultado el fin del conflicto social, que un crecimiento económico que pueda superar las distintas restricciones que se le puedan presentar - de oferta productiva, de balanza de pagos, de calificaciones de la mano de obra, etcétera- sería la solución definitiva a los problemas económicos del país. En el mundo de la seguridad social, esta utopía implicaba que las protecciones atadas a la condición laboral -contributivas- serían universales en un país de pleno empleo sostenido en el tiempo, y que los problemas de financiamiento de un sistema de reparto se resolverían solos en presencia de una tasa de crecimiento de la productividad persistentemente positiva, con sus consecuentes salarios reales en alza. Al agotarse estas utopías, reaparece la necesidad de que el Estado intervenga en el conflicto social a partir de políticas públicas concretas, segmentadas, heterogéneas. Los atisbos de extensión de la seguridad social hacia poblaciones marginadas por la vía de coberturas no contributivas pueden pensarse en este sentido. La necesidad de institucionalizar el déficit, de entenderlo como parte del sistema y no como un problema a resolver, o una anomalía, también.

\section{LA SEgURIDAd SOCIAL NeOliberal en SU ETAPA AUtORItARIA (1978 - 1983)}

Procedemos ahora a analizar las principales propuestas de reforma de la seguridad social llevadas a debate por la dictadura cívico-militar. Nos referimos a dos episodios distintos: por un lado, las distintas propuestas formuladas entre 1978 y 1979 para privatizar el sistema previsional y convertirlo en un esquema de capitalización, una alternativa similar a la que fuera aprobada en el Chile de Pinochet en 1981; por el otro, la eliminación de las contribuciones patronales a la seguridad social a mediados de 1980. 
En ambos casos se pusieron de manifiesto los conflictos al interior del régimen de facto entre los sectores vinculados a la tecnocracia neoliberal -en el Ministerio de Economía e instituciones satélite- y aquellos asociados al corporativismo católico -que permanecieron incólumes en el Ministerio de Bienestar Social-. El conflicto abierto entre los distintos sectores del gobierno de facto puede seguirse desde las obras de Canelo (2008) y Osuna (201 1; 2012), pero también puede sintetizarse en la siguiente cita tomada de Feldman, Isuani y Golbert (1988) en un clásico texto sobre la historia del sistema previsional argentino:

"el gobierno militar combinó durante buena parte de su administración un frente monolítico e impenetrable frente a la sociedad y una significativa fragmentación en el reparto de poder y en el control del aparato del Estado. En esas condiciones, a la Secretaría de Seguridad Social le tocó ocupar una posición de relativa autonomía logrando establecer una relación de negociación y conflicto con quienes decidían los rumbos de la política económica, particularmente durante el Ministerio de Martínez de Hoz (Feldman et al., 1988, pág. 15)".

\subsection{Las propuestas de creación de un régimen previsional de capitalización}

Las propuestas para convertir al sistema previsional de reparto administrado por el Estado en uno de capitalización gestionado por empresas privadas se originaron en organismos que funcionaban en la órbita del Ministerio de Economía: una pertenece a Roque Fernández, economista del Centro de Estudios Macroeconómicos de la Argentina (CEMA), un think tank neoliberal fundado en 1978 cuyas principales publicaciones estaban vinculadas a la defensa y promoción de las políticas propuestas por Martínez de Hoz; la otra a Antonio Margariti, economista de tradición católica perteneciente a la Fundación para la Libertad, tradicional think tank liberal de la ciudad de Rosario, en este caso en vinculación con la Bolsa de Comercio de la Ciudad de Buenos Aires. Tomamos como fuentes los documentos oficiales de las propuestas, Margariti (1979) y Fernández (1980) ${ }^{4}$.

4 En realidad Fernández publicó dos documentos de trabajo en el CEMA en 1979, uno más contextual ("Hacia una reforma del sistema argentino de previsión social" y el otro basado en un modelo teórico de consumo intertemporal ("Previsión social y crecimiento económico"). Nos referimos aquí al primero de ellos, citando la versión publicada en la revista académica Desarrollo Económico en 1980, refiriéndonos sólo acotadamente al segundo documento, que se cita desde su redacción original, dado que nunca fue publicado en una revista. 
Nos adentramos en la propuesta elaborada por Roque Fernández, la cual, entendemos, toma como sustento los debates de la tradición neoclásica estadounidense que se inaugura entre los cincuenta y los sesenta con los trabajos de Paul Samuelson (1958), Albert Ando y Franco Modigliani (1963), Peter Diamond (1965), James Buchanan (1968) y Milton Friedman (1962; 1965), mas se sistematiza en los setenta a partir de la obra de Martin Feldstein (1974) con su propuesta de hipótesis del ciclo vital con endogeneidad de la edad de retiro. Una síntesis de este recorrido teórico puede encontrarse en Dvoskin (2014b).

El planteo de Fernández comienza con un dato: la tendencia, en el mediano plazo, al crecimiento de los aportes y contribuciones previsionales concurrente con un deterioro de los haberes reales, lo cual se debe, según el autor, a su forma de gestión (Fernández, 1980, pág. 477). En particular, sostiene que el principal problema es la pretensión redistributiva que tiene el sistema previsional, la cual entra en contradicción con la necesidad de igualar ingresos y egresos para asegurar su armonía financiera (Fernández, 1980, pág. 478). En este sentido, el análisis de Fernández parte de afirmar que en la naturaleza del sistema de jubilaciones y pensiones reside la necesidad de asegurar el equilibrio presupuestario, con lo que cualquier pretensión redistributiva tomaría la forma de un vicio o anomalía. Desde el principio, entonces, se descarta cualquier tipo de función solidaria de la seguridad social.

Fernández es consciente de que tendencias contrapuestas entre ingresos y egresos pueden explicarse por el simple hecho de que, al comenzar, todo sistema contributivo es superavitario, y que con el tiempo este superávit tenderá a desaparecer. Sin embargo, lo que sostiene es que "la abundancia de fondos estimula la prodigalidad legal, que a su vez hace factible tanto la ampliación de beneficios como la extensión del sistema a otros sectores de la actividad económica" (Fernández, 1980, pág. 480). Es decir, se reconoce el superávit inicial pero se plantea que este dio lugar a un uso indebido de los recursos, otorgándose más beneficios que los adecuados $y$, por ende, dando pie al vicio de la redistribución del ingreso que conllevaría a la crisis financiera del sistema. En el segundo documento agregará como causas la erosión por inflación y la sobreponderación de problemas coyunturales respecto de perspectivas estructurales (Fernández, 1979, pág. 20). En este sentido es que calificará al sistema previsional argentino entre 1950 y 1973 como un subsidio que inhibió el proceso de formación de capital (Fernández, 1979, pág. 19).

Este diagnóstico comparte con los postulados de los neoliberales y libertarios norteamericanos como Friedman y Buchanan la crítica a la injerencia estatal y a las pretensiones redistributivas de la seguridad social. Sin 
embargo, en términos teóricos, el autor recurre inmediatamente al marco teórico propuesto por la hipótesis del ciclo vital de Ando y Modigliani (1963), según la cual en un sistema de reparto la desconexión de los haberes previsionales con los aportes propios generaría un desincentivo al ahorro, y por ende, en los términos de la economía neoclásica, una caída del crecimiento económico. Sin hacer citas específicas, el autor plantea que "la introducción de un programa público de previsión social, del tipo que se reconoce con el nombre de reparto, puede reducir el ahorro y, consecuentemente, la formación de capital" (Fernández, 1980, pág. 488).

Fernández recupera asimismo la controversia planteada originalmente por Paul Samuelson (1958) -popularizada como Samuelson's controversy-, sosteniendo que si la tasa de crecimiento de la masa salarial es mayor a la tasa de interés se producirá una merma en el ahorro de la clase activa (Fernández, 1980, pág. 488). Este es el apartado teórico que se desarrolla en profundidad en el segundo, donde sostiene que algunas generaciones "con el sistema de reparto, aumentan su consumo a expensas del stock de capital que dejan a las generaciones futuras, lo que actúa inhibiendo el desarrollo económico" (Fernández, 1979, pág. 1). Como vemos, rápidamente Fernández incorpora, para el caso argentino, las lecciones de la tradición neoclásica estadounidense en materia de seguridad social. Recién cuando mencione la alternativa de un modelo que endogenice la edad de retiro el autor se referirá específicamente a Feldstein con nombre y apellido.

Otro argumento que incorpora se remonta tanto a Friedman como a Feldstein, pero sobre todo a John Brittain (1971), quienes han sostenido en distintas oportunidades que tanto aportes personales como contribuciones previsionales son pagados por los trabajadores. La explicación de Fernández, sin embargo, es peculiar: sostiene que en un contexto de movilidad internacional del capital la remuneración al mismo ha de ser equivalente entre distintos países, con lo que necesariamente las contribuciones patronales recaerán sobre el trabajador (Fernández, 1980, pág. 490). Lo que presenciamos no es otra cosa que la incorporación del enfoque monetario del balance de pagos, otra de las nuevas hipótesis que surgen de la restauración neoclásica en macroeconomía, al mundo previsional. Al pensarse el aporte como a cargo del trabajador y enfatizando en que en la práctica este esté desligado, por lo menos directamente, del beneficio jubilatorio, Fernández se permite entenderlo como un impuesto pagado por el trabajador.

Estos elementos le permiten concluir al autor que el sistema de reparto es a la vez contractivo y regresivo, siendo culpa de la intervención estatal la disminución en la formación de capital, la cual ha atentado tanto contra el 
crecimiento del país como contra la magnitud de los mismos beneficios previsionales vigentes. La alternativa propuesta, un sistema de capitalización, permitiría reducir esta pérdida por la intervención estatal generándose una relación directa entre aportes y beneficios, sólo mediada por la tasa de interés, sin afectar a la tasa de ahorro. Así, en sus propios términos, sugiere llevar a cabo "una reforma del sistema actual para instaurar paulatinamente un sistema de capitalización y seguro" (Fernández, 1980, pág. 497), lo cual implicaría "dar libertad a las generaciones jóvenes que entran por primera vez a la fuerza laboral a contratar rentas vitalicias en el mercado privado del seguro" (Fernández, 1980, pág. 498).

No sólo de Estados Unidos provienen las ideas neoliberales que sacudieron el debate económico en la Argentina de los años setenta. Otra fuente muy concreta, que también encuentra un correlato en las propuestas de reforma previsional, tiene su origen en la reforma social de la Alemania Federal de la segunda posguerra y llega a la Argentina varios años antes que la versión norteamericana. Los lineamientos centrales de este neoliberalismo alemán pueden sintetizarse en la categoría de "economía social de mercado" difundida por el canciller alemán Ludwig Erhard. Algunos exponentes teóricos de este movimiento intelectual son los economistas de tradición austríaca Ludwig von Mises y Friedrich von Hayek, mientras que uno de los principales exponentes en Argentina es Álvaro Alsogaray, quien también fuera ministro de Economía del país. Los fundamentos teóricos de esta escuela pueden rastrearse desde Foucault (2004) y de Büren (2014), mientras que una muestra de su pretensión de implementación en Argentina desde Alsogaray (1968). Resulta relevante señalar que en estas fundamentaciones, a diferencia del neoliberalismo de matriz norteamericana, son muy importantes los principios de la doctrina social de la lglesia, el de solidaridad y, en especial, el de subsidiariedad del Estado y el de reivindicación de los cuerpos intermedios, sobre los cuales se asentará la crítica al estatismo.

La pretensión de privatizar la seguridad social podría, en términos teóricos, insertarse perfectamente en las propuestas de reforma de esta escuela. Esto se desprende, sin ir más lejos, del famoso documento publicado en 1955 por Hans Achinger, Joseph Hoffner, Hans Muthesius y Ludwig Neundorfer -todos ellos profesores identificados con el pensamiento católico-, titulado Neuordnung der sozialen Leistungen, preparado como conjunto de recomendaciones de políticas sociales para el gobierno de Konrad Adenaver, enmarcado precisamente en los principios de solidaridad y subsidiariedad. Sin embargo, en Argentina este no fue un tópico preponderante para ellos hasta finales de los setenta, y allí es donde entra en escena Antonio Margariti con su libro titulado La seguridad social estatizada. 
Su punto de partida es la comparación entre dos fuentes primigenias de los modelos de protección social: la alemana y la inglesa. Mientras que el modelo alemán pone en un primer lugar la responsabilidad individual, y desde este principio construye sus instituciones de bienestar social, el modelo inglés hace énfasis en el asistencialismo y la garantía de condiciones mínimas. Sus principales exponentes son Beveridge y Keynes. Sobre esta base teórica -que no pondremos en discusión aquí, aunque bien vale su problematización- Margariti afirma que "en el fondo el proyecto nacional desarrollado a partir de 1947 y hasta 1976, bajo distintas denominaciones partidarias, no fue sino un plagio de las ideas británicas de Lord Beveridge y Lord Keynes" (Margariti, 1979, pág. 13).

En este sentido, la construcción del Estado social argentino, donde se incluyen los gobiernos peronistas, radicales y militares de todo el período tendría desde sus orígenes un vicio incorregible: la prioridad asignada a la garantía de mínimos vitales por sobre la responsabilización individual. El problema del Estado benefactor es que "su principio de igualdad distributiva le conduce a anular la competencia en rendir, al mismo tiempo que le lleva a desatar la competencia en exigir" (Margariti, 1979, pág. 15). Este énfasis en la necesidad de fomentar la competencia y los vicios que acarrea su reemplazo por una lógica estatista lleva rápidamente nuestras referencias a los fundamentos del pensamiento neoliberal, tal como fuera propuesto por Foucault.

Además, agrega que sostener un generoso Estado benefactor conlleva incrementos impositivos que atentan contra la posibilidad del ahorro, generándose un círculo vicioso de caída en la productividad (por falta de incentivos competitivos), inflación, caída del ahorro y crecimiento de la presión fiscal. En este sentido, su crítica a la protección social desde el Estado pasa a ser parte de una crítica mayor al keynesianismo como teoría económica. En este marco es que plantea su reforma, la cual se sostiene en que los cambios que han empezado a acontecer en la Argentina desde 1976 habilitan transformaciones ulteriores, una de las cuales es la de la seguridad social, inalterada hasta el momento. En este sentido,

"en momentos históricos tan solemnes, como el actual, en el que las fuerzas armadas argentinas se han comprometido a la reorganización de nuestras instituciones y a la remoción de todos los obstáculos para la grandeza nacional, sería un imperdonable error el mantener incólumne el amplio campo en que se desenvuelve la política social como si la misma fuera un territorio inexpugnable" (Margariti, 1979, pág. 19). 
Queda más que claro su alineamiento ideológico con la dictadura militar en curso. Si esta está avanzando hacia una des-estatización de la economía argentina, ¿̇por qué no avanzar también en la seguridad social? Al fin y al cabo, ha pretendido demostrar que esta característica, su estatalidad, es la responsable de todos sus males, en tanto "nuestro sistema de previsión social estatal forma parte de un edificio que aprisionó y empobreció a la economía argentina durante los últimos treinta años" (Margariti, 1979, pág. 35). Así,

"se ha erigido un sistema financiero, coercitivamente impuesto, por el que se le quita al individuo una enorme porción de su salario real y se le promete una protección obligatoria que, para colmo, la inflación frustra en su mayor parte. Nuestra estructura de la seguridad social, a fuerza de acumular normas y cargas sociales que nos agobian, es propia de una sociedad masificante, avasalladora de los derechos individuales con el peor de los autoritarismos, porque quita a cada uno lo que es suyo propio y luego devuelve una parte mediante la ficción en la que cada cual cree que le regalan lo de otros. La solución a nuestros males en materia de seguridad social, igual que en otras materias sociales, consiste en terminar con el monopolio estatal. Es decir, abrir el mercado para que la sana competencia permita que cada cual elija libremente el seguro social de su preferencia" (Margariti, 1979, pág. 25).

Como vemos, a diferencia de Fernández, el eje principal no está puesto en criterios de eficiencia económica sino en postulados éticos, políticos e incluso jurídicos, más allá de las bases económicas de la crítica. En este sentido, los fundamentos económicos le sirven a Margariti como elemento legitimador de sus postulados éticos.

"La seguridad social es uno de los pilares de nuestro Estado benefactor con los que se pretendió escamotear la vigencia de las leyes económicas y distribuir lo que no se había producido. Pero, el milagro de la multiplicación de los panes y de los peces no puede ser repetido por el Estado aunque pretenda convertirse en una nueva providencia. Porque así como una nación no puede consumir más de lo que haya creado en bienes y servicios, del mismo modo cada habitante no puede conquistar más auténtica seguridad que la seguridad que en total se haya conseguido mediante el rendimiento productivo de la economía nacional" (Margariti, 1979, pág. 35). 
En este fragmento Margariti no se está refiriendo a otra cosa que a la Ley de Say. No poder consumir más que lo que se hubiera producido, más allá de que en una primera lectura parece una aseveración inocua, supone una causalidad desde la oferta (lo producido) hacia la demanda (lo que se consume), y esta es la característica central de la citada ley. Por supuesto, esto se fundamenta y referencia en términos teóricos cuando el autor afirma que "como se trata entonces de administrar recursos escasos destinados a cubrir necesidades en aumento, vuelve por sus fueros la economía clásica apoyada en el análisis marginalista de Viena" (Margariti, 1979, pág. 42). Postulada entonces la matriz teórica, Margariti se permite afirmar que la seguridad social argentina "constituye pues un verdadero aparato de antiahorro, generador de un negativo efecto de disminución de las inversiones propias de los asalariados y de la consecuente paralización del progreso social" (Margariti, 1979, pág. 51). Así, por un camino distinto, llega a la misma conclusión a la que arriba Fernández: que el sistema de reparto disminuye el ahorro y, vía la Ley de Say, cae también la inversión y con ella la economía en su conjunto.

Concluye su texto con su propuesta de reforma, la cual se sostendrá a partir de un conjunto de principios, entre los que se destacan: que la previsión personal tenga prioridad frente a la ayuda estatal, que el Estado no asuma responsabilidades que pueden asumir otros y que sólo quien contribuye puede recibir beneficios de la seguridad social (Margariti, 1979, pág. 58). Para el caso del sistema previsional, sugiere que se establezca una jubilación mínima automática restringida y limitada, una jubilación adicional optativa y la conformación de un fondo previsional de ahorro garantizado (Margariti, 1979, pág. 65). Sin que se la entienda como contradictoria, podríamos asociar a la jubilación mínima con el principio cristiano de la solidaridad, que debe realizarse entre pares y no desde el Estado. Los componentes principales del sistema previsional propuesto, la jubilación optativa y el fondo de ahorro garantizado, reproducen en líneas generales las consignas a favor de los modelos de capitalización individual que hemos presentado.

Como vemos, se trata de una propuesta fundamentada por otros canales, con un fuerte influjo católico y una recurrencia ética a un conjunto de principios básicos de sociabilidad, donde el problema económico se supedita al problema ético pero a la vez le da herramientas y fundamentos. El resultado, en cambio, es muy similar al que obtenemos siguiendo el recorrido del neoliberalismo norteamericano, que desemboca en Argentina a través de Roque Fernández y el CEMA. 


\subsection{La eliminación de las contribuciones patronales a la seguridad social}

Quizás la medida económica más importante de la dictadura en materia de seguridad social fue la eliminación de las contribuciones patronales acontecida a mediados de 1980, la cual fue compensada, en términos de las cuentas de la seguridad social, con la asignación de recursos tributarios para el pago de los haberes. La medida, más allá de que se venía discutiendo abiertamente desde fines de 1979, fue anunciada públicamente el 10 de julio de 1980. Alrededor de este acontecimiento es que se puso de manifiesto nuevamente el conflicto al interior del régimen entre los funcionariados del Ministerio de Economía y de Bienestar Social, pero al mismo tiempo habilitó la intervención de otros sectores, representantes sindicales y de jubilados y referentes de partidos políticos, los cuales se manifestaron mayoritariamente en contra de la decisión de la cartera económica, y de representantes empresariales, quienes en general se manifestaron a favor. Claramente se trata de una medida que trasciende a la seguridad social en sí, y que puede pensarse como parte de una estrategia más general tendiente a reducir la participación de los trabajadores en el ingreso nacional. Tal como lo presentan Laura Golbert y Emilia Roca,

"con el objetivo de bajar aún más el costo laboral, se eliminaron las contribuciones patronales a la seguridad social [...], las que fueron sustituidas por impuestos [...] de carácter regresivo. De forma tal que, el financiamiento de la seguridad social y las jubilaciones, quedaban a cargo de los ciudadanos, en especial de los propios trabajadores o incluso de aquellos que, por no tener un trabajo formal, habían quedado fuera del sistema" (Golbert y Roca, 2010, pág. 41).

De acuerdo con Florencia Osuna, en términos programáticos, para el Ministerio de Economía "la seguridad social no debía ser [...] una carga ni para el Estado ni para el empresariado" (Osuna, 2012, pág. 115). Lo que nos interesa aquí es comprender de qué manera se sustentan teóricamente tanto la medida como sus críticas, de modo tal que la controversia en cuestión nos sirve para comprender con qué argumentos el discurso neoliberal intentaba imponerse y qué resistencias encontraba en aquellos años.

El anuncio de la eliminación, el 10 de julio de 1980, se hizo en conjunto con otras medidas económicas, como el aumento de las alícuotas del impuesto al valor agregado, en parte para financiar al sistema previsional. El encargado del mismo fue el ministro de Economía, quien calificó al hecho como "una nueva etapa en la aplicación del programa económico", 
cuyo objetivo primordial es "propiciar una reducción de los costos industriales" 6 . En un artículo del día 12 de julio, el periodista de Clarín-uno de los principales periódicos de la ciudad de Buenos Aires- Daniel Muchnik, intentando exponer la versión oficial sobre las medidas expresa que

"la eliminación de las cargas sociales representa, en opinión de las autoridades del Ministerio de Economía, un blanqueo del salario, [...] las empresas no pagarán más en negro y cierto segmento de la población podrá invertir sus ingresos en el país, en vez de girarlos al exterior, en tren de resguardo"7.

De este modo se reproduce un argumento clásico de las cosmovisiones neoliberales, que ya encontramos antes en referencia al sistema previsional, pero aquí se refiere principalmente al mundo del trabajo: la existencia de cargas o impuestos implicaría un incentivo a la evasión, con lo que al reducir o eliminar las mismas el resultado sería una mayor formalización de la economía, en este caso del mercado de trabajo. Si a esto agregamos los argumentos ya expuestos por Roque Fernández respecto a que finalmente quien paga las contribuciones patronales es el trabajador debido a la igualación de las tasas de ganancia a nivel mundial, nos encontramos con que no solo esta eliminación incentivaría la formalización sino que, además, de hecho sería un descuento para el propio trabajador, y no una ganancia adicional para el empresario.

Argumentos similares expusieron, al respecto, dirigentes empresarios como Jorge Aguado, de Confederaciones Rurales, y Juan Pirán, de la Sociedad Rural Argentina, respecto a las reducciones de costos implicadas ${ }^{8}$, así como Federico Zorraquín, de la Asociación de Bancos Argentinos, más enfático en términos de la adscripción ideológica a la gestión de Martínez de Hoz, quien sostuvo que las nuevas medidas económicas

"significan una nueva e importante etapa en la instrumentación de un programa de cambio estructural realmente sin precedentes que

5 Clarín, 11 de julio de 1980, Buenos Aires, "Martínez de Hoz anunció otra etapa económica", págs. 10 y 11 .

6 lbíd., pág. 10.

7 Muchnik, Daniel, "El significado del 'paquete'", en Clarín, 12 de julio de 1980, Buenos Aires, págs. 8 y 9 .

8 Clarín, 12 de julio de 1980, Buenos Aires, "Tres opiniones empresarias", págs. 6 y 7. 
apunta a la modernización y mayor eficiencia de nuestra economía sometiéndola a la dura ley de la competencia interna y externa y rescatando el papel de la empresa privada como motor del progreso económico"l.

Asimismo, las medidas recibieron el beneplácito de la del periódico La Nación -otro de los principales periódicos de la ciudad-, que inaugura su artículo editorial central del día 12 de julio manifestando que

"las medidas anunciadas por el ministro de Economía constituyen un apreciable aporte para la disminución de los costos internos, en el sector agropecuario y en el sector industrial, con lo que se da un buen paso adelante hacia la corrección de la desproporción existente entre los mismo y el tipo de cambio"10.

Sin embargo, al mismo tiempo en este artículo se criticaba que la baja en las alícuotas sea compensada con asignaciones de recursos tributarios, no llevándose a cabo un ejercicio de racionalización del Estado que permitiera reducir efectivamente el gasto público. Asimismo, Clarín expuso distintas voces a favor y en contra, haciendo hincapié en el delicado equilibrio entre reducción de costos laborales y mantenimiento de los haberes previsionales que debió asumir el gobierno militar. Por ejemplo, las primeras voces del Ministerio de Bienestar Social no manifestaron una crítica abierta sino que intentaron desligarse de la medida y anunciar que la misma no tendría efectos sobre los haberes. Por un lado, el ministro Jorge Fraga manifestó que la decisión de eliminar las contribuciones patronales partió del Ministerio de Economía y, por el otro, el secretario de Seguridad Social Santiago de Estrada afirmó que no se trataba de una disminución de los ingresos previsionales sino de un cambio en sus fuentes de financiación ${ }^{11}$.

Sin embargo, sí fueron más enfáticas desde el principio otras voces opositoras a las medidas, sobre todo aquellas provenientes de representantes gremiales. Por ejemplo, el dirigente Luis Etchezar, del gremio ferroviario "La Fraternidad" sostuvo que "ahora que el régimen previsional dependerá en gran parte de Economía y, por lo tanto estará directamente inscripto

9 lbíd., pág. 6.

10 La Nación, 12 de julio de 1980, Buenos Aires, "Las nuevas medidas económicas", pág. 6.

11 Clarín, 13 de julio de 1980, Buenos Aires, "Fraga: la anulación del aporte patronal partió de Economía", págs. 2 y 3. 
dentro de la política económica, a los jubilados les espera una muy probable situación de indigencia extrema"12. Asimismo, el dirigente Enrique Venturini, secretario general del sindicato de electricistas navales, sostenía que las medidas tomadas

"son una nueva corroboración de que la política económica carga sobre las espaldas de los trabajadores [...en tanto...] lo que impacta a primera vista es la eliminación del aporte empresario del 15 por ciento para la caja de jubilaciones. Este hecho representa el desmantelamiento de un sistema que con sus vicios y virtudes demostró ser una herramienta idónea en defensa de los jubilados"13.

También manifestaron rápidamente su oposición representantes de los distintos partidos políticos. Deolindo Bittel, del Partido Justicialista, expuso su pesimismo basado en "la filosofía que inspira al ministro Martínez de $\mathrm{Hoz}^{\prime 14}$. El economista radical Roque Carranza, quien más tarde fuera designado ministro de Obras Públicas, expresó que las medidas "constituyen una nueva forma de hacer caer el financiamiento de los gastos públicos sobre el sector asalariado"15. En tanto, el dirigente del Partido Intransigente y exgobernador de la Provincia de Buenos Aires, Oscar Alende, fue mucho más contundente al expresar que las mencionadas medidas "constituyen un último y desesperado esfuerzo para justificar una política destinada a poner al país dentro de la túnica impuesta por unas cien grandes transnacionales que pretenden controlar el mundo para el año 2000"16.

Sin embargo, las voces más contundentes en contra de la eliminación de las contribuciones patronales provinieron de las asociaciones de jubilados y pensionados. Por un lado, el Centro Nacional de Jubilados y Pensionados, de la Asociación de Trabajadores del Estado, manifestó que "es imposible admitir que con la supresión del aporte de una de las partes se mantendrá sin alteraciones el nivel de regularidad alcanzado"17, desconfiando así de la promesa de cubrir la caída en la recaudación previsional con asignaciones presupuestarias. Por otro, la Mesa Coordinadora Nacional de Organizaciones de Jubilados y Pensionados señaló que "la disminución

12 Clarín, 13 de julio de 1980, Buenos Aires, "Crítica gremial", pág. 3.

13 Clarín, 12 de julio de 1980, Buenos Aires, "Rechazo de los gremios", págs. 6 y 7.

14 Clarín, 12 de julio de 1980, Buenos Aires, "Cuestionamiento político", pág. 6.

15 lbíd., pág. 5.

16 La Nación, 12 de julio de 1980, Buenos Aires, "Santiago de Estrada manifestó que no disminuirán los aportes", pág. 9.

17 Clarín, 20 de julio de 1980, Buenos Aires, "Oposición de jubilados", pág. 6. 
de la recaudación previsional se acentúa con la libre importación de los productos que se fabrican en el país" 18 , frente a lo cual "los industriales nacionales deben ser protegidos con menos impuestos, imposibilitando la importación de productos de fabricación nacional" ${ }^{19}$, convocándose así no solo a la revisión de la medida reciente sino cuestionando, ante todo, los efectos de la desindustrialización del país sobre la calidad de vida de los trabajadores, tanto activos como pasivos. También sostuvo que los aportes patronales garantizan "la continuidad de las jubilaciones y pensiones, garantía que desaparece si dependemos de hipotéticos sobrantes del impuesto IVA"20, sobre todo, especulando con que "el IVA será descargado en los precios que aumentarán en forma vertiginosa con mayor sufrimiento para las capas populares"21.

Hacia finales de julio los funcionarios del Ministerio de Bienestar Social comenzaron a responder con críticas un poco más fuertes a las medidas tomadas por Economía, en particular a partir de la creación de una comisión interministerial encargada de reglamentar las mismas. Entre otras cosas, según se señala en Clarín, Bienestar Social llevó a esta comisión el reclamo de "un reaseguro que la provisión automática de los recursos para los jubilados y pensionados"22, a lo que Economía habría respondido que eso dependería de la disponibilidad de recursos: es decir, que las limitaciones de financiamiento, ahora incorporando las partidas tributarias compensatorias, estarían por encima de la satisfacción de las necesidades de los jubilados y pensionados.

Como vemos, la eliminación de las contribuciones patronales se encontró con fuertes resistencias, tanto de la sociedad civil como de otros sectores del gobierno, pero pudo imponerse. Damos cuenta, entonces, de lo incipiente que era el discurso económico neoliberal en la Argentina de fines de los setenta y principios de los ochenta, dado que necesariamente debía debatir con otros paradigmas y no gozaba de un status hegemónico. En este sentido es que encontramos en las alocuciones de otros actores, como asociaciones de jubilados, representantes sindicales o referentes de partidos políticos ideas que llevan a la necesidad de recuperar las categorías del desarrollismo, o por lo menos lo imperioso de un desarrollo indus-

18 Ibíd., pág. 6.

19 Clarín, 23 de julio de 1980, Buenos Aires, "Protesta de jubilados", pág. 7.

20 lbíd., pág. 7.

21 Ibíd., pág. 7.

22 Clarín, 27 de julio de 1980, Buenos Aires, "Panorama político: entre Bolivia y los aportes", pág. 8 . 
trial y una recuperación del Estado benefactor contrarios a los designios de la política económica. Sí resulta interesante lo rápido que los discursos empresariales, o por lo menos de sus principales cámaras, absorben el paradigma neoliberal.

\section{La Seguridad social neOliberal en SU etapa democrática (1983 - 1993)}

El retorno de la democracia en diciembre de 1983 abrió muchos frentes de conflicto que habían estado vedados debido al contexto de la dictadura. En particular, muchos de ellos estarán asociados al terrible escenario económico y social heredado del régimen de facto, caracterizado por aumentos significativos de la pobreza y la indigencia y caídas de los salarios reales. No nos encontramos, aun, con un escenario de abierto desempleo. Sobre esta base, en este acápite recorremos los debates acaecidos en torno a la reforma de la seguridad social en los diez años que van desde la recuperación de la democracia hasta la gran reforma previsional de 1993, la cual creó un esquema mixto público-privado, en el cual los trabajadores podían optar por adherir al sistema de reparto gestionado por el Estado o pasarse a uno de capitalización individual, administrado por entidades privadas. Estos debates incluyen la declaración de emergencia previsional por parte del presidente Raúl Alfonsín en noviembre de 1986, los debates sobre la crisis del mismo hacia fines de los ochenta y las distintas propuestas de crear un sistema de capitalización que no prosperaron como sí lo hizo la que se convertiría en Ley 24.241 en 1993.

\subsection{Los ochenta: la recuperación democrática y la emer- gencia previsional}

Presentamos aquí una breve síntesis de las principales políticas de seguridad social de la década del ochenta, caracterizada, ante todo, por la persistente crisis, lo cual no constituía una excepción para una economía que en su conjunto estaba sumergida en una profunda crisis. No nos detendremos en aspectos puntuales sino que intentaremos mostrar cómo la idea misma de crisis de la seguridad social fue configurando un campo propicio para la difusión cada vez más recurrente de las ideas neoliberales. Podemos introducirnos a este período citando a Laura Golbert y Emilia Roca, quienes sostienen que, hacia 1983,

"la funesta herencia que dejó la dictadura en términos de desintegración social, económica y política demandaba tiempo y esfuerzo para revertir este proceso. Pero el gobierno democrático se encontró ante un círculo vicioso: la crítica situación económica y social le otor- 
gaba escasos grados de libertad para ejecutar políticas tendientes a reparar el daño causado a la sociedad por la dictadura, no permitiendo transitar por el camino virtuoso del crecimiento. El aumento de la deuda externa generada por la dictadura y la deuda social interna son los dramáticos indicadores de esta situación" (Golbert y Roca, 2010, pág. 42).

Ya en su discurso inaugural como presidente, el 10 de diciembre de aquel año, Alfonsín se refería a la seguridad social como un área prioritaria. Sostenía que

"nuestra concepción de la promoción social es inseparable de la indispensable participación popular en la solución de los problemas de cada grupo comunitario. Poca ventaja de largo alcance puede esperarse del mero paternalismo del Estado en el tratamiento de tales problemas, como tampoco la ofreció en su tiempo la aislada beneficencia privada" 23 .

Es decir, se retoma un pretendido posicionamiento intermedio entre lo estatal y lo privado, tal como propusieran los intelectuales socialcristianos en las décadas anteriores. Nuevamente, será la participación de los interesados lo que permita encauzar ello, y de allí que la primera consigna en materia de seguridad social sea la mayor autonomía financiera. En este caso, entendemos, el posicionamiento intermedio surge de una "concepción de la política social inspirada en los valores de solidaridad, justicia social y participación" 24 , pero que al mismo tiempo no puede desligarse de las condiciones críticas de la coyuntura argentina, de los problemas de financiamiento y de las causalidades que se le asignaban al Estado como responsable de esa situación. En este sentido, más allá de una propuesta que recupera las proclamas de solidaridad social que ciertos sectores del régimen de facto habían vilipendiado, no puede desentenderse del discurso anti-estatal que empieza a aflorar.

En cuanto a las medidas tomadas, una de las primeras fue la restitución de las contribuciones patronales, aunque en guarismos sobre el salario

23 En Mensaje Presidencial a la Asamblea Legislativa, 10 de diciembre de 1983. Disponible en http://www.elhistoriador.com.ar/documentos/raul_alfonsin/

24 Ibíd. 
inferiores a aquellos anteriores a su eliminación por el gobierno militar. De esta manera, las promesas de recuperación de una seguridad social que respondiera a las demandas de sus beneficiarios se vieron cada vez más constreñidas por la recurrente insuficiencia de fondos. De acuerdo con Nicolás Arceo, Mariana González y Nuria Mendizábal,

"la fragilidad financiera del sistema jubilatorio persistió y se profundizó tanto por la significativa expansión de la informalidad laboral y la evasión fiscal como, aunque en menor medida, por el envejecimiento poblacional producto del aumento de la esperanza de vida y por el descenso de la natalidad. Esto implicó que el Estado se retrasara en el pago de los beneficios, lo que sumado a la pérdida del valor real de los haberes por la inflación generó una caída significativa en las condiciones de vida de los jubilados (Arceo et al., 2009, pág. 8)".

Este proceso llevó a la promulgación, el 28 de noviembre de 1986 del decreto 2196/86, el cual establecía la declaración de emergencia previsional, la cual implicaba, entre otras cosas, la suspensión de los pagos de las sentencias por juicios previsionales, además de una modificación a la baja de los haberes en general y una reducción de topes que determinaban los haberes máximos. Cabe resaltar dos fragmentos de los considerandos, los cuales nos permiten comprender de qué manera entendían los funcionarios del gobierno la crisis del sistema previsional. En primer lugar, se aclara en el texto que el sistema

"opera desde hace muchos años en régimen de reparto puro, lo que significa que todas las sumas que se recaudan en un período determinado se aplican íntegramente al pago de las prestaciones correspondientes al mismo período, sin que exista posibilidad alguna de ampliar el gasto más allá de los recursos económicos realmente disponibles" 25 .

En este sentido, parecieran ser las pautas institucionales las que inhiben la posibilidad de aumentos en los gastos de la seguridad social en tanto no se registren aumentos en sus ingresos, lo que refuerza la importancia que los años neoliberales le asignaron a los equilibrios financieros. Lo que 
sigue, entonces, es la explicación de la falta de recursos, la cual se dirige a las políticas económicas implementadas por los gobiernos anteriores.

"Equivocados criterios de política económica que prevalecieron durante largos años en etapas anteriores de la vida nacional, determinaron en su tiempo una considerable reducción del aparato productivo del país, originando de este modo una situación general que hoy se procura corregir con gran esfuerzo, y cuyas consecuencias evidentes han sido el desempleo, la disminución del nivel del salario real y el incremento del número de personas dedicadas a las tareas por cuenta propia, todo lo cual [...] ha tenido un fuerte impacto negativo sobre la capacidad del sistema previsional para recaudar recursos genuinos, ya que sus fuentes de financiamiento directo"26.

De este modo parece quedar claro que no habrá solución a la crisis previsional en tanto y en cuanto no se restablezca la capacidad productiva del país, con lo que los problemas de la seguridad social son, en realidad, expresiones de la crisis económica general antes que problemas propios del sistema. Bajo este contexto es que el mismo año la Secretaría de Seguridad Social, a cargo de Emilio Capuccio, propuso una reforma previsional -que no fue aprobada y tuvo muchas resistencias- tendiente a institucionalizar los elementos de emergencia: reconocer la imposibilidad de pago del 82 por ciento móvil, darle estatus permanente al financiamiento tributario, integrar una prestación básica no contributiva y eliminar los regímenes previsionales de privilegio ${ }^{27}$.

Un año después de la mencionada declaración de emergencia previsional (los días 24 y 25 de noviembre de 1987) tiene lugar el seminario titulado "La reforma del sistema previsional argentino", organizado por la Secretaría de Seguridad Social y la Fundación Friedrich Ebert, de la cual surge, como síntesis de los acuerdos alcanzados, el texto La reforma del sistema previsional argentino, a cargo de Javier Slodky, coordinador del evento como representante de la mencionada fundación, en 1988.

Una de las principales novedades es el reconocimiento de los efectos nocivos sobre la cobertura de la seguridad social y su financiamiento causados por "el impacto de las diversas formas de trabajo precario y cuentapropismo" (Slodky, 1988, pág. 15). Verificamos aquí la introducción de un problema que será explícitamente central en los debates desde los noventa

26 lbíd.

27 Detalles sobre esta propuesta se encuentran en Isuani y San Martino (1993, págs. 43 - 47). 
en adelante, pero que hasta el momento no había sido tenido en cuenta de manera sustantiva. De acuerdo con la presentación realizada por Aldo Isuani, en aquel momento director de política social del Ministerio de Salud y Acción Social, en el mencionado seminario, "el problema del empleo informal, o autónomo, o no estructurado, constituye [...] uno de los mayores desafíos planteados a cualquier estrategia universalista, o simplemente extensiva, de la seguridad social en nuestro hemisferio"28. Esto se debe, claro está, a que "no hay posibilidades para la seguridad social sobre bases contributivas para expandirse mucho más allá del mercado formal de trabajo" ${ }^{29}$. En esta línea, relativamente novedosa en términos de énfasis, es que se comprende la alocución del secretario de Seguridad Social, Roberto Bigatti, al afirmar que

"una de las propuestas básicas que el Poder Ejecutivo tiene planteada es establecer una prestación básica única y universal frente a determinadas contingencias que no se cubran por el sistema contributivo. Esta prestación básica y universal deberá atender a los ciudadanos que por vejez o invalidez pasaron determinada edad y no tienen ni ellos ni su grupo familiar una cobertura social o del sistema previsional" ${ }^{\prime 30}$.

Claramente, las consecuencias abiertas en materia de cobertura de la seguridad social por el avance de la informalidad, y sobre todo por la escasísima proyección a una reversión de esta tendencia, hacen resurgir la agenda de la protección no contributiva, por lo menos en el nivel del discurso público. Pareciera ser este el camino para reforzar los principios solidarios de la seguridad social en tiempos de insuficiencia de fondos. Sin embargo, queda claro que la persecución de los objetivos universalistas no responde a principios rectores en abstracto sino a las falencias del sistema vigente. Esto se entiende desde otra afirmación de Bigatti, quien sostiene que es necesario "separar lo que es la franja de protección social que debe atender la seguridad social de la franja contributiva de la misma" ${ }^{31}$.

28 Expresado por Aldo Isuani en el seminario "La reforma del sistema previsional argentino", 24 y 25 de noviembre de 1987, Buenos Aires. En Slodky (1988, pág. 25).

29 lbíd., págs. $26-27$.

30 Expresado por Roberto Bigatti en el seminario "La reforma del sistema previsional argentino", 24 y 25 de noviembre de 1987, Buenos Aires. En Slodky (1988, Anexo I, pág. 92).

31 lbíd., págs. $91-92$. 
El gobierno de Alfonsín se cerrará, entonces, sin grandes reformas en materia de seguridad social. Incluso, como ya adelantamos, se dejó sin efecto la declaración de emergencia previsional en 1988 a partir de la sanción de fallos judiciales adversos a la misma. Sin embargo, en materia previsional, entendemos que el amplio debate acaecido durante la década, y en particular el énfasis puesto en las falencias presupuestarias del mismo -más allá de la prevalencia de posiciones favorables a mantener el esquema de reparto- servirá de base para los debates y las reformas de la década siguiente.

\subsection{Los noventa: la concreción del sueño neoliberal y la privatización}

Siguiendo nuestro esquema conceptual, si el período que va desde mediados de los setenta hasta los ochenta puede pensarse como de tensión y confrontación entre el paradigma desarrollista y el neoliberal -el primero no termina de morir, el segundo no termina de nacer-, donde este último no consigue erigirse, aun, como hegemónico, será en los años noventa cuando encontremos el cierre del ciclo de cambio paradigmático y la consolidación del neoliberalismo como el discurso social hegemónico en la Argentina.

En términos de la seguridad social, el ejemplo más claro será la reforma previsional de 1993 que modificó el régimen vigente para convertirlo en uno mixto de capitalización privada y reparto público. Sin embargo, resulta necesario inscribir a la reforma previsional dentro del conjunto de profundas transformaciones que en la década del noventa se empezaron a proponer en materia de administración pública, regulación económica, mercado de trabajo y protección social en general, en coincidencia con la asunción a la presidencia de Carlos Saúl Menem y principalmente a partir del nombramiento como ministro de economía de Domingo Cavallo y de la sanción de su principal ley, la ley de convertibilidad, en 1991. De acuerdo con Osvaldo Battistini y Juan Montes Cató,

"desde la década de los noventa se sucedieron modificaciones profundas y estructurales en Argentina, modificaciones que si bien venían esbozándose desde tiempo atrás, asumen un corpus homogéneo a partir de la reforma del Estado, el proceso de reestructuración económica y reconversión productiva. Dichos procesos generaron cambios de orden jurídico, económico y social. Estas reformas impactaron significativamente en las relaciones laborales a través de la aplicación de la denominada flexibilización laboral, asumida como 
una de las herramientas para llevar a cabo la adaptación de dichas relaciones al nuevo contexto productivo" (Battistini y Montes Cató, 2000, pág. 64).

Hacia principios de la década la reforma del sistema previsional ya se había convertido en un tema central de la agenda. De acuerdo con Guillermo Alonso, ya en 1991 sus principales lineamientos se habían dado a conocer, principalmente desde la asunción de la nueva conducción de la secretaría de Seguridad Social, a cargo de Walter Schulthess. Esta gestión, que reemplazó a Santiago de Estrada, implicó, de acuerdo con Alonso,

"un salto cualitativo en capacidades técnicas y, además de representar la opción política por introducir un sistema de capitalización individual, permitió una mayor homogeneidad de la acción gubernamental, subordinando claramente el área de Seguridad Social a las estrategias más generales de la gestión macroeconómica" (Alonso, 1998, págs. 599 - 600).

El primer proyecto oficial llegó al Congreso en junio de 1992. Sin embargo, la premisa según la cual la crisis del sistema previsional argentino sería resuelta si se adoptara un sistema de capitalización se había apropiado de la agenda pública, al punto de que se habían presentado numerosos proyectos en tal sentido en los últimos años, entre los que se destacan ${ }^{32}$ : a) los de carácter mixto (de capitalización y reparto), como el presentado por la Fundación de Investigaciones Económicas Latinoamericanas (FIEL) en $1987^{33}$, el presentado por el diputado Eduardo del Río en 1989 o el elaborado por la Unión Industrial Argentina (UIA), presentado en 1990, b) los de permanencia del reparto pero habilitando un régimen de capitalización complementario y optativo, como el que presentó Santiago de Estrada desde la Secretaría de Seguridad Social en $1990^{34}$ y c) los que proponían

32 Detalles, síntesis y comparaciones de todas las propuestas que se enumeran a continuación pueden encontrarse en Isuani y Sanmartino (1993, págs. 47 - 64) y en Jáuregui (1994, págs. $32-41)$.

33 Ver la propuesta completa en FIEL (1987). 
emular el esquema chileno, como el propuesto por la Asociación de Bancos Argentinos, también de $1990^{35}$. Volviendo al proyecto de Schulthess de 1992, Alonso sostiene que

"el proyecto oficial proponía la creación de un nuevo sistema sustentado en dos regímenes: uno, público y de reparto, y otro, de capitalización individual, que otorgarían una prestación previsional unificada. [...] Todos los trabajadores menores de 45 años [...] se incorporarían obligatoriamente a un régimen de capitalización individual, que sería financiado con los aportes de los afiliados durante su vida laboral activa. Los mayores de 45 años podrían pasarse voluntariamente de sistema" (Alonso, 1998, pág. 601).

Resulta interesante citar algunas líneas del mencionado proyecto de ley, en el cual podemos encontrar algunos de los fundamentos económicos principales de la propuesta de reforma. En principio, resalta que el proyecto se presenta a sí mismo, desde sus primeras líneas, como una alternativa para resolver un problema financiero. Antes que pensarse como la consecución de un logro, se lo ve como la solución a un conflicto. Afirma el mensaje del Poder Ejecutivo que el sistema previsional vigente

"se basa en el otorgamiento de jubilaciones y pensiones mediante un sistema de reparto. En su estado ideal, el mismo se financia básicamente mediante el aporte de los trabajadores [...] y las contribuciones de los empleadores. Sin embargo, no existe una correlación entre los aportes pagados por un individuo a lo largo de su vida activa y los beneficios que el sistema le otorga. Esta desvinculación

34 Marcela Jáuregui entiende que este proyecto "proponía la continuidad del sistema de reparto administrado por el Estado, manteniéndolo como el principal sistema previsional hacia el futuro dados los altísimos costos que acarrearía la transición hacia un sistema privado de capitalización mientras el Estado debe hacerse cargo de sus jubilados y pensionados con fondos cada vez más reducidos. Plantea, sin embargo, la existencia de un sistema optativo de capitalización." (Jáuregui, 1994, pág. 32).

35 Isuani y San Martino sintetizan los objetivos de esta propuesta en: "acotar el sistema de reparto a un período limitado en el tiempo, pasando gradualmente a otro fundado en la capitalización individual, disminuir la incidencia de las cargas sociales sobre el salario, crear un mercado de capitales que canalice el ahorro generado por el sistema de capitalización y acreciente la inversión local y asignar al Estado el rol de fiscalización y control del nuevo sistema" (Isuani y San Martino, 1993, pág. 59). 
[...] se pone de manifiesto en la manera de determinar los haberes $[\ldots]$, que hace referencia al salario percibido en los últimos años previos al cese de actividad. Una consecuencia de la disociación entre aportes y beneficios es la falta de garantías respecto a la capacidad del sistema para generar los recursos necesarios con el fin de dar cumplimiento a las obligaciones emanadas de la propia ley. Hasta cierto punto, estas deficiencias han tendido a cubrirse con la participación del producido de algunos recursos tributarios [...]. La necesidad de recurrir a estas fuentes alternativas de financiamiento se ha tornado creciente con el transcurso del tiempo, lo que revela las limitaciones del sistema para autofinanciarse, y la dependencia respecto a fuentes de financiamiento externas" ${ }^{\prime 36}$.

Como vemos, el texto se inicia con una crítica al financiamiento no genuino del sistema, el cual, en virtud de la crisis, había proliferado en años recientes $^{37}$. Al mismo tiempo, agrega que muchas de las redistribuciones operadas al disociarse aportes y beneficios son regresivas, y suma como causas de la crisis del sistema el cambio demográfico, los cambios en el mercado de trabajo -crecientes informalidad y tercerización- y las mal implementadas moratorias ${ }^{38}$.

El proyecto continuará la tradición iniciada hace muchos años respecto a resaltar los principios rectores de la seguridad social. A los principios tradicionalmente señalados, universalidad, solidaridad, equidad, etc., se agregará uno nuevo y central: el de la libertad:

"sin dejar de aceptar la condición que el gobierno no puede desentenderse de la problemática previsional, dadas sus hondas repercusiones sociales, deberá consentir dentro de ciertos límites que los individuos manifiesten su voluntad en cuanto a disposiciones que

36 Mensaje 1560 y proyecto de ley de modificación del sistema nacional de previsión social. Sesión de la Cámara de Diputados del 27 de agosto de 1992. En la versión taquigráfica, pág. 3639.

37 Isuani y San Martino calculan que entre 1985 y 1992 entre un 20 y un 30 por ciento del financiamiento de la seguridad social fue a través de recursos tributarios (Isuani y San Martino, 1993, pág. 27).

38 Mensaje 1560 y proyecto de ley de modificación del sistema nacional de previsión social. Sesión de la Cámara de Diputados del 27 de agosto de 1992. En la versión taquigráfica, págs. $3640-3642$. 
incidirán en sus ingresos futuros como pasivos. Volúmenes de garantías, formas de distribución de los ingresos previsionales, etcétera, deberán, dentro de lo posible, quedar a la libre elección de las personas" 39 .

\section{Entonces,}

"en el nuevo régimen el Estado dejará de detentar la exclusividad en el manejo y asignación de los fondos que aportan los trabajadores con fines previsionales. Pero tampoco se reemplazará el monopolio de gestión de un ente público por el monopolio de uno privado. Una diversidad de instituciones públicas y privadas participará en la gestión del nuevo sistema previsional" 40 .

Al mismo tiempo, "para asegurar una aceptable rentabilidad se pondrán en marcha los mecanismos de la competencia, pero con pautas de inversión estrictas que privilegien la seguridad de los fondos depositados" 41 . El resultado es un proyecto de ley que "propone un régimen de financiamiento viable, más justo y más eficiente que el vigente" 42 . En este sentido vemos cómo el énfasis en la competencia y en la eficiencia de la asignación individual o privada, sumado a la desconfianza en las capacidades estatales para hacerse cargo de las decisiones, se pone de manifiesto con claridad.

El proyecto no habría de aprobarse rápidamente -principalmente por la reticencia de legisladores oficialistas- y comenzaría 1993 siendo uno de los principales temas de la agenda. Sin ir más lejos, en su discurso de apertura de sesiones el presidente Menem señalaba que "1993 tiene para este presidente una prioridad principalísima: los jubilados" 43 .

39 Ibíd., pág. 3642.

40 lbíd., pág. 3643.

41 lbíd., pág. 3643.

42 lbíd., pág. 3644.

43 Mensaje presidencial a la Asamblea Legislativa, $1^{\circ}$ de mayo de 1993. Disponible en Honorable Senado de la Nación, Dirección Publicaciones, "Mensaje Presidencial del Dr. Carlos Saúl Menem a la Honorable Asamblea Legislativa", Buenos Aires, pág. 27. 
Frente a las resistencias que tuvo el proyecto en sus inicios, el secretario de Seguridad Social Walter Schulthess publicó desde la CEPAL, en junio de 1993 y junto con Gustavo Demarco, consultor del Programa de las Naciones Unidas para el Desarrollo (PNUD), el informe titulado Argentina: evolución del sistema nacional de previsión social y propuesta de reforma. Este texto puede considerarse como el informe académico principal en términos de sustento del proyecto enviado al parlamento. Allí se sostiene que el sistema previsional propuesto se inspira en los siguientes principios:

"libertad de elección de los cotizantes y acceso a nuevas alternativas de pensiones; eficiencia, transparencia y credibilidad a partir de un sistema de pensiones financiera y actuarialmente solvente; equidad en la relación entre aportes y beneficios, y solidaridad con los cotizantes de menores ingresos" (Schulthess y Demarco, 1993, pág. 14).

El texto se organiza a partir de la ejemplificación y cuantificación de la radical crisis que atraviesa el sistema previsional, en tanto el objetivo principal es la demostración de que sólo una reforma estructural, y no parches o modificaciones parciales, pueden repararlo. La variable central que explica la crisis es, en un sistema de reparto como el argentino, la tasa de sostenimiento, es decir el cociente entre los aportantes y los beneficiarios. Para Shulthess y Demarco, la principal evidencia en las últimas décadas, agravada en los últimos años, es una caída de la misma. Sostienen los autores que entre las causas de este fenómeno

"pueden [...] distinguirse factores de carácter demográfico (envejecimiento poblacional), económico (crecimiento de la informalidad) y relativos a la administración del sistema (amplitud de la cobertura y laxitud en los criterios para el otorgamiento de beneficios). Los dos primeros revisten, claramente, carácter estructural, y exógeno a la acción de variables de política previsional. En cambio, los aspectos vinculados a la administración del sistema pueden ser útiles para revertir (al menos parcialmente) la caída en la relación entre aportantes y beneficiarios" (Schulthess y Demarco, 1993, pág. 89).

Así, de mantenerse el sistema de reparto, "el régimen carece de viabilidad si no se introducen cambios sustanciales en su forma de financiamiento, que busquen fuentes de ingresos más allá de la base salarial, o si no se disminuye el compromiso de pago al nivel que permite la tasa de sostenimiento (Schulthess y Demarco, 1993, pág. 128)". Es entonces que se 
fundamenta a favor de un régimen mixto de capitalización y reparto, entendiendo que la combinación entre ambos tiene simultáneamente en cuenta

"los objetivos de justicia social y equidad. Los componentes de reparto se orientan a compensar a aquellas personas que evidencien una menor capacidad de acumulación. El de capitalización, por su parte, se orienta a estimular la capacidad de ahorro con fines previsionales mediante el otorgamiento de más elevadas prestaciones a quienes aporten más" (Schulthess y Demarco, 1993, pág. 182).

Finalmente, se trataría de un proyecto que conjugaría sin contradicciones los múltiples principios rectores que un sistema de seguridad social debe seguir:

"la materialización del principio de equidad se logra mediante el régimen de capitalización, que genera beneficios proporcionales al esfuerzo individual. Sin embargo, el sistema es también solidario, pues su componente de prestación básica universal posee un efecto fuertemente redistributivo, llamado a incidir de manera significativa en los haberes que perciban aquellos trabajadores cuyos ingresos se encuentren por debajo del promedio de la economía. El principio de libertad se encuentra presente en diversas instancias que brindan a los afiliados la posibilidad de elegir la AFJP [...]. La eficiencia habrá de lograrse mediante un diseño basado en la diversidad de instituciones para una diversidad de funciones." (Schulthess y Demarco, 1993, págs. 206 - 207).

Como vemos, el documento incorpora, matizados por la necesidad de mantener los principios de solidaridad, los argumentos acerca de las bondades de la capitalización en lo que refiere al incentivo al ahorro y, por ende, desde un enfoque teórico que lo entiende como motor de la acumulación, al crecimiento. En particular, es significativo el reconocimiento al rol virtuoso que la competencia ejerce en la asignación de los recursos, lo cual sostendría la primacía de la gestión privada por sobre la gestión pública.

Luego de varias idas y vueltas, negociaciones y reformulaciones, muy bien descritas en Isuani y San Martino (1993), Alonso (1998) y Narcy (2003), el proyecto fue aprobado en septiembre de 1993 para empezar a regir a partir de 1994. Se puso en marcha la mayor transformación de la seguridad social en la historia argentina hasta el momento, dando cuenta del grado de consenso alcanzado por el ideario neoliberal pero al 
mismo tiempo, a la luz de las resistencias y concesiones que tuvo el proyecto -como plantea también Alonso, significativamente mayores que en otras privatizaciones llevadas a cabo por el gobierno de Menem ${ }^{44}$, dando cuenta de la continuidad, en los imaginarios sociales, de la idea de la seguridad social como un espacio de solidaridad y de realización de la justicia social, principios que incluso tuvieron que ser incorporados y defendidos desde el discurso oficial.

\section{Conclusiones}

Este trabajo nos propone pensar interrogantes que continúan abiertos. En primer lugar, nos permite problematizar las nociones del neoliberalismo, saliendo de aquellas que lo entienden como un paradigma estanco y automáticamente hegemónico, y que en el caso argentino lo inscriben como impuesto de modo categórico en marzo de 1976. Aquí, al postular una inscripción paulatina y rugosa, constantemente en disputa, desde sus primeras proclamas en los setenta hasta su concepción hegemónica en los noventa, podemos discutir de qué modo las ideas económicas se van imponiendo y ajustando a las coyunturas.

En segundo lugar, en lo que refiere estrictamente al sistema de seguridad social, resulta interesante revisar cómo se fue construyendo el programa privatizador. Mostramos los primeros intentos de establecimiento de un sistema de capitalización en 1979, las secuelas de ese intento fallido, su rechazo tajante hacia los ochenta y su reaparición en el contexto de la crisis de fines de la década. Más aun, la retórica utilizada para fundamentar el proyecto de ley que finalmente se impondrá en 1993 reconoce las limitaciones de la idea en términos de legitimación, lo que se expresa también en la necesidad que tuvo el gobierno de negociar con distintos sectores. En este sentido, incluso en los noventa lejos está el neoliberalismo de alcanzar un consenso tal que no permite ni siquiera discusión, más allá de su creciente legitimación.

Por último nos referimos a las ideas económicas. Resulta significativo el recurso cada vez más asiduo de elementos propios de la economía neoclásica. Nos referimos, entre otras cosas, a conclusiones que se basan en teorías de los precios que se sostienen en enfoques de oferta y demanda en lugar de pensarse como márgenes sobre costos, explicaciones monetaristas de la inflación, definiciones de las ganancias como contribuciones del capital, asunciones de ineficiencia de las cargas tributarias en base al 
desincentivo inversor y, principalmente, aceptaciones implícitas de la Ley de Say, es decir, de que la oferta crea su propia demanda y el ahorro es el que determina la inversión. Sin embargo, como mostramos, este recorrido tampoco está exento de debates y conflictos, permaneciendo, aun en los noventa, resabios de teorías económicas que habían sido hegemónicas en el pasado (keynesianas, estructuralistas y desarrollistas).

En síntesis, ofrecemos y sometemos a discusión y crítica un sendero para pensar la historia económica y la economía política desde una perspectiva poco habitual, la de las ideas implícitas en la agenda pública, en particular emplazadas en las políticas públicas.

\section{Referencias}

\subsection{Bibliografía}

ACHINGER, H., HÖFFNER, J., MUTHESIUS, H. y NEUNDÖRFER, L. (1955): Neuordnung der sozialen Leistungen. Denkschrift auf Anregung des Bundeskanzlers. Colonia, Greven.

ALONSO, G. (1998): "Democracia y reformas: las tensiones entre decretismo y deliberación. El caso de la reforma previsional argentina". Desarrollo Económico,Vol. 38, № 150, pp. 595 - 626.

ALSOGARAY, Á. (1968): Bases para la acción política futura. Buenos Aires, Atlántida.

ANDO, A. y MODIGLIANI, F. (1963): "The "life cycle" hypothesis of saving: aggregate implications and tests". The American Economic Review, Vol. 53, $N^{\circ} 1$, pp. $55-84$.

ARCEO, N., GONZÁLEZ, M. y MENDIZÁBAL, N. (2009): La evolución del sistema previsional argentino. Buenos Aires, CIFRA.

BASUALDO, E. (2006): Estudios de historia económica argentina: desde mediados del siglo XX a la actualidad. Buenos Aires, Siglo XXI Editores.

BATTISTINI, O. y MONTES CATÓ, J. (2000): "Flexibilización laboral en Argentina. Un camino hacia la precarización y la desocupación". Revista Venezolana de Gerencia, Vol. 5, N 10, pp. $63-89$.

BRITTAIN, J. (1971): "The incidence of social security payroll taxes". The American Economic Review, Vol. 61, № 1, pp. $110-125$.

BUCHANAN, J. (1968): "Social insurance in a growing economy: a proposal for radical reform". National Tax Journal, Vol. 21, № 4, pp. 386 - 395. CANELO, P. (2008): "Las "dos almas" del proceso. Nacionalistas y liberales durante la última dictadura militar argentina (1976 - 1981)". Páginas, Vol. 1, N¹, pp. $69-85$. 
DE BÜREN, P. (2014): La escuela austríaca de economía, expansión y difusión de sus ideas fuerza. Argentina 1959 - 1989. Buenos Aires, Universidad de Buenos Aires.

DIAMOND, P. (1965): "National debt in a neoclassical growth model". The American Economic Review, Vol. 55, № 5, pp. 1126 - 1150.

DVOSKIN, N: (2014a): "La política previsional en el tercer gobierno de Perón (1973 - 1974): entre las perspectivas económicas y las condicionalidades políticas" XXIV Jornadas de Historia Económica. Rosario, Asociación Argentina de Historia Económica.

DVOSKIN, N. (2014b): "Los jubilados al mercado. Una genealogía teórica de la propuesta neoliberal de reforma previsional entre los ' 50 y los ' 70 y su arribo en Argentina". Cuadernos de Economía Crítica, NN 1, pp. 101 - 122. DVOSKIN, N. (2015a): "Del derecho a la economía: las principales referencias teóricas en la política de seguridad social argentina (1949 - 1983)". Estudios Sociales del Estado, No 1, pp. 139 - 169.

DVOSKIN, N. (2015b): La seguridad social en los años desarrollistas (1957 - 1968). Moreno, UNM Editora.

FELDMAN, J., ISUANI, E. y GOLBERT, L. (1988): Maduración y crisis del sistema previsional argentino. Buenos Aires, Centro Editor de América Latina. FELDSTEIN, M. (1974). "Social security, induced retirement, and aggregate capital accumulation". Journal of Political Economy, Vol. 82, № 5, pp. 905 - 926.

FERNÁNDEZ, R. (1979): Previsión social y crecimiento económico. Buenos Aires, Centro de Estudios Macroeconómicos de Argentina.

FERNÁNDEZ, R. (1980). "Hacia una reforma del sistema argentino de previsión social". Desarrollo Económico, Vol. 19, N 76, pp. 477 - 498.

FIEL (1987): El fracaso del estatismo. Una propuesta para la reforma del sector público argentino. Buenos Aires, Sudamericana - Planeta.

FOUCAULT, M. (2004): Nacimiento de la biopolítica. Buenos Aires, Fondo de Cultura Económica.

FRIEDMAN, M. (1962): Capitalism and Freedom. Chicago, University of Chicago Press.

FRIEDMAN, M. (1965): "Transfer payments and the social security system". National Industrial Conference Board Record. 2.7 - 10. Nueva Yorkm, The Conference Board.

GOLBERT, L. y ROCA, E. (2010): "De la Sociedad de Beneficencia a los derechos sociales". Revista de Trabajo, N 8, pp. 29 - 51.

ISUANI, A. y SAN MARTINO, J. (1993): La reforma previsional argentina. Opciones y riesgos. Buenos Aires, Miño y Dávila. 
JÁUREGUI, M. (1994): Crisis y reformulación del régimen previsional argentino. Buenos Aires, Instituto de Estudios sobre Estado y Participación.

MARGARITI, A. (1979): La seguridad social estatizada. Buenos Aires, Bolsa de Comercio de la Ciudad de Buenos Aires.

NARCY, M. J. (2003): La reforma previsional en Argentina: privatización de los beneficios, estatización de los costos. La Plata, Universidad Nacional de La Plata.

OSUNA, M. F. (2011). "Las políticas de Seguridad Social durante la última dictadura militar argentina (1976 - 1983). Análisis de la dinámica de oposición y consenso en torno a una conflictiva trama de actores estatales y corporativos". VI Jornadas de Jóvenes Investigadores. Buenos Aires, Instituto de Investigaciones Gino Germani - Universidad de Buenos Aires.

OSUNA, M. F. (2012): "Católicos y tecnócratas. Diagnósticos, políticas y discusiones en torno a la previsión social durante la última dictadura militar". Páginas, Vol. 4, № 6, pp. $101-121$.

RAPOPORT, M. (2012): Historia económica, política y social de la Argentina. Buenos Aires, Emecé.

SAMUELSON, P. (1958): "An exact consumption-loan model of interest with or without the social contrivance of money". Journal of Political Economy, Vol. 66, N 6, pp. $467-482$.

SCHULTHESS, W. y DEMARCO, G. (1993): Argentina: evolución del sistema nacional de previsión social y propuesta de reforma. Santiago de Chile, CEPAL.

SOLDKY, J. (1988): La reforma del sistema previsional argentino. Buenos Aires, Ministerio de Trabajo y Seguridad Social.

\subsection{Fuentes consultadas}

Cámara de Diputados de la Nación, versiones taquigráficas de sesiones.

Decretos y Leyes Nacionales.

Diario Clarín, Buenos Aires.

Diario La Nación, Buenos Aires.

Mensaje Presidencial a la Asamblea Legislativa, 10 de diciembre de 1983. Disponible en http://www.elhistoriador.com.ar/documentos/raul_alfonsin/ Mensaje presidencial a la Asamblea Legislativa, $1^{\circ}$ de mayo de 1993. Disponible en Honorable Senado de la Nación, Dirección Publicaciones, "Mensaje Presidencial del Dr. Carlos Saúl Menem a la Honorable Asamblea Legislativa", Buenos Aires. 